\title{
A Complementary Electrochromic Device with Highly Improved Performance Based on Brick-Like Hydrated Tungsten Trioxide Film
}

\author{
Zhihui Jiao ${ }^{1}$, Jinmin Wang ${ }^{1}$, Lin $\mathrm{Ke}^{2}$, Xiao Wei Sun ${ }^{1,3, *}$, and Hilmi Volkan Demir ${ }^{1,4,5}$ \\ ${ }^{1}$ School of Electrical and Electronic Engineering, Nanyang Technological University, Nanyang Avenue, \\ Singapore 639798, Singapore \\ ${ }^{2}$ Institute of Material Research and Engineering, $A^{*}$ STAR (Agency for Science, Technology and Research), \\ Research Link, Singapore 117602, Singapore \\ ${ }^{3}$ Department of Applied Physics, College of Science, and Tianjin Key Laboratory of Low-Dimensional Functional Material \\ Physics and Fabrication Technology, Tianjin University, Tianjin 300072, China \\ ${ }^{4}$ Department of Electrical and Electronics Engineering, Department of Physics, UNAM-Institute of Materials \\ Science and Nanotechnology, Bilkent University, Bilkent, Ankara 06800, Turkey \\ ${ }^{5}$ School of Physical and Mathematical Sciences, Nanyang Technological University, Nanyang Avenue, \\ Singapore 639798, Singapore
}

\begin{abstract}
Uniform and well adhesive nanostructured hydrated tungsten trioxide $\left(3 \mathrm{WO}_{3} \cdot \mathrm{H}_{2} \mathrm{O}\right)$ films were grown on fluorine doped tin oxide (FTO) substrate via a facile and template-free crystal-seed-assisted hydrothermal method by addition of ammonium sulfate $\left(\left(\mathrm{NH}_{4}\right)_{2} \mathrm{SO}_{4}\right)$ and hydrogen peroxide $\left(\mathrm{H}_{2} \mathrm{O}_{2}\right)$. $\mathrm{X}$-ray diffraction $(\mathrm{XRD})$ studies indicated that the films are of orthorhombic structure. Scanning electron microscopy (SEM) and high resolution transmission electron microscopy (HRTEM) analysis showed that the film was composed of brick-like nanostructures with a preferred growing direction along (002). The influence of seed layer, $\left(\mathrm{NH}_{4}\right)_{2} \mathrm{SO}_{4}$ and $\mathrm{H}_{2} \mathrm{O}_{2}$ on the products were also studied. The film showed good cyclic stability, comparable switching speed and coloration efficiency $\left(30.1 \mathrm{~cm}^{2} \mathrm{C}^{-1}\right)$. A complementary electrochromic device based on the film and Prussian blue depicted highly improved color contrast, coloration/ bleaching response (1.8 and $3.7 \mathrm{~s}$ respectively) and coloration efficiency $\left(164.6 \mathrm{~cm}^{2} \mathrm{C}^{-1}\right)$.
\end{abstract}

Keywords: Electrochromic, Nanostructure, Tungsten Oxide, Complementary.

\section{INTRODUCTION}

Electrochromism is the phenomenon of reversible changes in the optical properties of a material during electrochemical redox processes, which can be applied in energy-efficient smart windows, antiglare rear-view mirrors and displays. ${ }^{1-12} \mathrm{~A}$ lot of materials exhibit electrochromism, including many transition metal oxides $\left(\mathrm{WO}_{3}, \mathrm{NiO}\right.$ and $\left.\mathrm{MoO}_{3}\right)$, Prussian blue (PB) and some organic conducting polymers (poly (aniline) and poly (3, 4-propylene-dioxythiophene)). , $^{81,13-17}$ Compared with organic electrochromic (EC) polymers, inorganic EC materials such as $\mathrm{WO}_{3}$ and $\mathrm{PB}$ have the advantage of being inherently more stable against over oxidation and UV radiation. ${ }^{13,18}$ For practical applications, the EC materials need to be assembled into thin films on conductive

\footnotetext{
*Author to whom correspondence should be addressed.
}

substrate and incorporated into an EC device, which is conventionally a multilayer structure with one EC layer countered with one ion storage layer or one complementary EC layer, and one intermediate ion conductor layer. Compared with a single EC layer device, a complementary device depicts improved optical regulation, coloration efficiency and cyclic stability. ${ }^{19,20}$

Among various EC materials, tungsten trioxide $\left(\mathrm{WO}_{3}\right)$ has attracted intensive attention due to its distinguished EC properties such as high coloration efficiency, good color-memory effect, large color contrast and good cyclic stability. ${ }^{1,3,13,21}$ By alternately applying suitable negative and positive electrical voltages, the $\mathrm{WO}_{3}$ film displays blue color and colorless due to the double injection/extraction of the cations $\left(\mathrm{H}^{+}, \mathrm{Li}^{+}\right)$and electrons correspondingly. Compared with the amorphous structure, crystalline $\mathrm{WO}_{3}$ demonstrates better durability in acidic electrolyte due to 
its denser structure that results in a slower dissolution rate. However, bulk crystalline $\mathrm{WO}_{3}$ particles usually lead to slow switching responses and small coloration efficiency, resulting from the high diffusion resistance of ions. Thus, nanostructured $\mathrm{WO}_{3}$ films with large specific area and porous morphologies are desired, and faster switching response and better durability are expected. ${ }^{18,22,23} \mathrm{Up}$ until now, various methods have been reported to fabricate $\mathrm{WO}_{3}$ films (dense or porous) on various substrates, such as sputtering, chemical vapor deposition, electrodeposition, sol-gel and hydrothermal. ${ }^{23-35}$ Hydrothermal synthesis is a facile, cost-effective and environmentally friendly technique, which offers diversity for substrate selection and the possibility of controlling the characteristics (thickness, structure size, morphology and porosity) of the asprepared films. In fact, $\mathrm{WO}_{3}$ hydrates $\left(\mathrm{WO}_{3} \cdot \mathrm{xH}_{2} \mathrm{O}\right)$ or "tungstic acids" are generally obtained in liquid-phase synthesis routes. Compared with the dehydrated $\mathrm{WO}_{3}$, the hydrothermally grown hydrated $\mathrm{WO}_{3}$ films have demonstrated improved stability and efficiency, ${ }^{36,37}$ and further improvement could be achieved by increasing the porosity and incorporating a suitable complementary layer.

Prussian blue [PB, iron (III) hexacyanoferrate (II)], a synthetic coordination-compounded transition metal hexacyanometallates, is a well-known anodically colored EC material. It is reported that an electrodeposited PB film exhibits electrochromism between blue and colorless with a fast response ( less than $100 \mathrm{~ms})$ and a high durability after $5 \times 10^{6}$ cycles. ${ }^{38}$ However, the PB film shows little absorption in the IR region which hinders its applications in energy efficient smart windows. The combination of $\mathrm{WO}_{3}$ and $\mathrm{PB}$ in a complementary device has demonstrates improved optical modulation, response speed and coloration efficiency. For example, Kraft and Rottmann reported large-area laminated EC glass composed of electrodeposited $\mathrm{WO}_{3}$ and $\mathrm{PB}$ films. ${ }^{15,16}$ The device shows a coloration efficiency of $\sim 140 \mathrm{~cm}^{2} / \mathrm{C}$ and transmittance modulation $\mathrm{T} \%$ of $\sim 70 \%$ at $630 \mathrm{~nm}$, both are higher than that of single component EC devices. ${ }^{18,23,34,38}$ However, the $\mathrm{WO}_{3}$ film adopted by Kraft et al. is a relatively smooth and dense thin film prepared by an electrodeposition process, for which specific and costly facilities are required. Hence, more efforts need to be done to explore a cost effective method to assemble porous and highly adhesive nanostructured $\mathrm{WO}_{3}$ films.

In this paper, we revisit this device structure with a porous brick-like nanostructured hydrated $\mathrm{WO}_{3}$ films grown via a facile and low cost crystal-seed-assisted hydrothermal approach. As-prepared hydrated $\mathrm{WO}_{3}$ films are uniform and highly adhesive, exhibiting good cyclic stability, comparable coloration efficiency and fast switching response. The performance is further highly improved by incorporating a PB layer in a complementary EC device. The device demonstrates increased color contrast, switching speed and coloration efficiency, which can be applied in energy-efficient smart windows and large area information displays.

\section{EXPERIMENTAL DETAILS}

\subsection{Preparation of Crystal Seeds Layers, Precursor and Hydrothermal Treatment}

The procedures for preparing crystal seeds layers are similar to our previous report, which can be found elsewhere. ${ }^{34}$ In a typical experiment for preparing the precursor, $\mathrm{Na}_{2} \mathrm{WO}_{4} \cdot 2 \mathrm{H}_{2} \mathrm{O}(0.065 \mathrm{~g})$ was dissolved into $20 \mathrm{~mL}$ of de-ionized water and then $\mathrm{H}_{2} \mathrm{O}_{2}(0.2 \mathrm{~g})$ and $\left(\mathrm{NH}_{4}\right)_{2} \mathrm{SO}_{4}$ $(0.045 \mathrm{~g})$ was added into the solution under intense stirring. Pure $\mathrm{HCl}$ was dropped into the above solution until the $\mathrm{pH}$ value reaches 1.5 . For the purpose of comparison, solutions without adding $\mathrm{H}_{2} \mathrm{O}_{2}$, $\left(\mathrm{NH}_{4}\right)_{2} \mathrm{SO}_{4}$ or both were also prepared. The as-prepared solutions were transferred into autoclaves as hydrothermal precursors. The seed coated FTO glasses were lie at the bottom of the autoclaves and the hydrothermal growth was performed at $180{ }^{\circ} \mathrm{C}$ for $18 \mathrm{~h}$. High transparent films were grown on the substrate after washing away the adhered precipitate by di-water. Then the films were dried in atmosphere.

\subsection{Electrodeposition of $P B$ and Preparation of EC Device}

The electrodeposition of PB film was carried out by a conventional three-electrode system, where a clean FTO glass $\left(1.5 \times 2 \mathrm{~cm}^{2}\right)$ served as the working electrode, a platinum sheet as the counter electrode, and a $\mathrm{Ag} / \mathrm{AgCl} / 1 \mathrm{M}$ $\mathrm{KCl}$ as the reference electrode. The electrodeposition bath contained $10 \mathrm{mM} \mathrm{K}_{3} \mathrm{Fe}(\mathrm{CN})_{6}, 10 \mathrm{mM} \mathrm{FeCl}{ }_{3}$ and $0.1 \mathrm{M}$ $\mathrm{KCl}$ and the electrodeposition was carried out by applying a constant cathodic current density of $50 \mu \mathrm{A} \mathrm{cm} \mathrm{cm}^{-2}$ for $130 \mathrm{~s}$. Then the $\mathrm{WO}_{3}$ (hydrated) working electrode and $\mathrm{PB}$ counter electrode were sandwiched together with hot-melt Surlyn spacers. A liquid electrolyte composed of $0.3 \mathrm{M} \mathrm{LiClO}_{4}$ in $\gamma$-butyrolactone $(\gamma$-BL) was introduced between the two electrodes by capillary action. Finally the cell was sealed by epoxy with a structure of FTO $\|$ hydrated $\left(\mathrm{WO}_{3}\right) \| \gamma$-BL $\left(\mathrm{LiClO}_{4}\right)\|\mathrm{PB}\|$ FTO.

\subsection{Characterizations}

The phases of the as-grown films were identified by $\mathrm{X}$-ray powder diffraction (XRD, Siemens), using $\mathrm{Cu}$ $\mathrm{K} \alpha(\lambda=0.15406 \mathrm{~nm})$ radiation. The phase structures were characterized by Raman spectroscopy (Renishaw in Via). X-ray photoelectron spectroscopy (XPS) data were obtained on a Kratos AXIS spectrometer with monochromatic Al-K $\alpha(1486.71 \mathrm{eV}) \mathrm{X}$-ray radiation. The morphologies of the as-prepared thin films were observed by field emission scanning electron microscope (FESEM, JSM 6340). High-resolution transmission electron microscopy 
(HRTEM) image was obtained by a JEM-2100 microscope using an accelerating voltage of $200 \mathrm{kV}$. Thicknesses of the films were measured by a TENCOR P-10 Surface Profiler. The UV-vis transmittance spectra were measured using a UV-vis spectrophotometer (JESCO V670). Electrochemical measurements were performed by a threeelectrode system (VersaSTAT 3F Potentiostat/Galvanostat) with $0.3 \mathrm{M} \mathrm{LiClO}_{4}$ in $\gamma$-BL as the electrolyte, Pt sheet as the counter electrode and $\mathrm{Ag} / \mathrm{AgCl} / 1 \mathrm{M} \mathrm{KCl}$ as the reference electrode.

\section{RESULTS AND DISCUSSION}

The X-ray powder diffraction patterns of the bare FTO substrate and the as-prepared thin film are illustrated in Figure 1(a). The pattern of the substrate is indexed to tin oxide layer. For the hydrothermally grown film, characteristic peaks of hydrated $\mathrm{WO}_{3}$ were obtained. All the diffraction peaks can be well indexed to orthorhombic hydrated $3 \mathrm{WO}_{3} \cdot \mathrm{H}_{2} \mathrm{O}\left(\mathrm{H}-\mathrm{WO}_{3}\right)$ phase with lattice constants of $a=7.345, b=12.547$ and $c=7.737 \AA$, agreeing well with the standard diffraction pattern (JCPDF
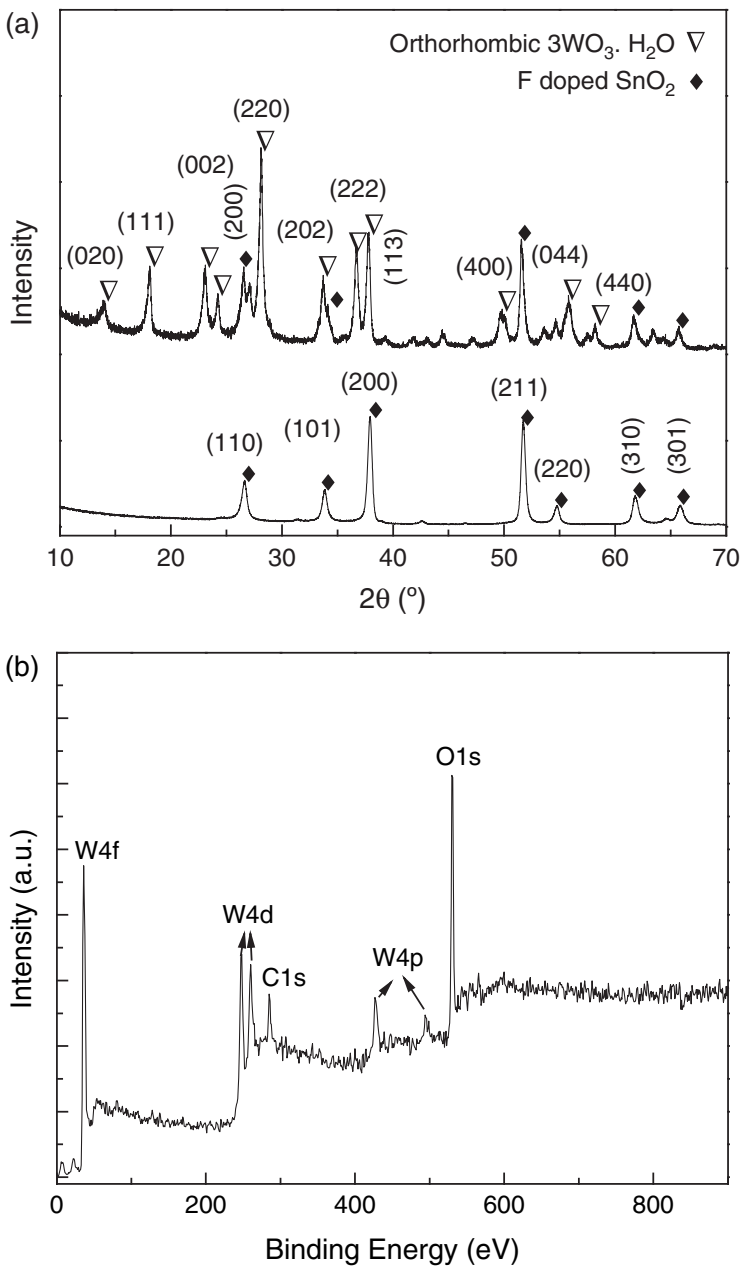

87-1203). And no impurity peaks were observed on the pattern, implying high purity of the $\mathrm{H}-\mathrm{WO}_{3}$ film. The sharp peaks indicate the good crystalline quality of the as-fabricated film. The X-ray photoelectron spectroscopy (XPS) and Raman spectra of the nanobrick $\mathrm{H}-\mathrm{WO}_{3}$ film were also investigated and shown in Figures 1(b) and (c), respectively. All the peaks appeared on the spectra can be well assigned to be $\mathrm{H}-\mathrm{WO}_{3}$ and no other impurities were detected, coincide with the XRD result. The orthorhombic $3 \mathrm{WO}_{3} \cdot \mathrm{H}_{2} \mathrm{O}$ phase contains two type of structure unites: one is conducted by six oxygen atoms surrounded one centered $\mathrm{W}$ atom that shares the six corner oxygen atoms with adjacent octahedra, and the other is containing a coordinative water molecule with a prolonged $\mathrm{W}-\mathrm{OH}_{2}$ bond and a shorted $\mathrm{W}=\mathrm{O}$ bond (shown in Fig. 1(d)). ${ }^{39}$ It is clear that the EC performance of $\mathrm{WO}_{3}$ is closely related to its level of crystallization. ${ }^{13}$ Crystalline $\mathrm{WO}_{3}$ films with large surface area and porous morphologies are expected to achieve a good stability, high coloration efficiency values and fast response. 23,39

Figures 2(a) and (b) show the top-view SEM images of the as-synthesized $\mathrm{H}-\mathrm{WO}_{3}$ film under different

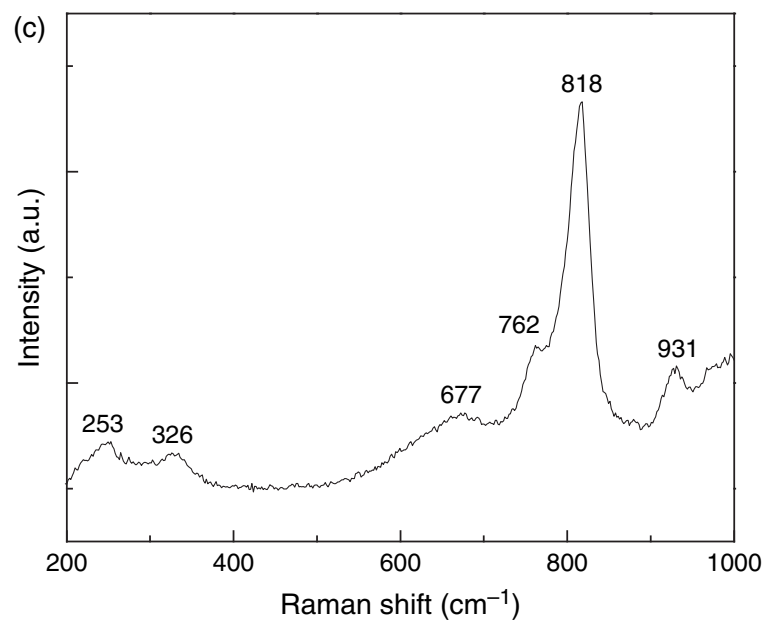

(d)

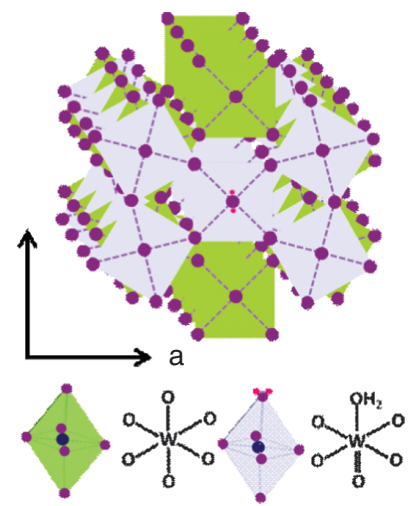

Fig. 1. (color online) (a) XRD patterns of the bare FTO substrate and the as-synthesized thin films. (b) Wide scanning XPS spectra of the as-prepared nanobrick film. (c) Raman spectra of the film. (d) Schematic illustration of the orthorhombic $3 \mathrm{WO}_{3} \cdot \mathrm{H}_{2} \mathrm{O}$ structure. 

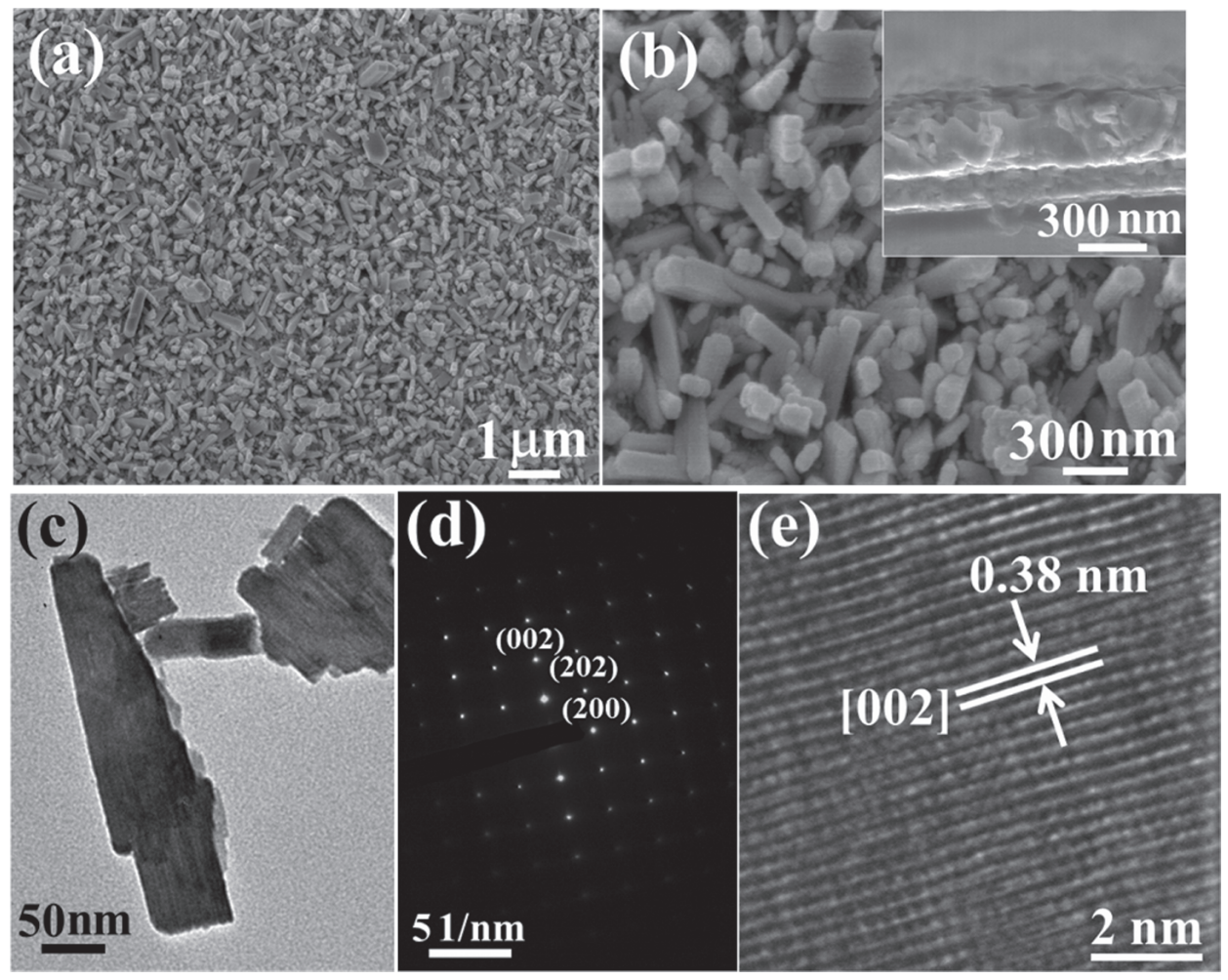

Fig. 2. (a) and (b) FESEM images of the $\mathrm{H}-\mathrm{WO}_{3}$ thin films under different magnifications. (c) TEM image of the nanobrick scratched from the film. (d) SAED pattern of the nanobrick. (e) HRTEM image of the nanobrick.

magnifications. It can be seen that the film is composed of brick-like nanostructures with average size of $\sim 100 \mathrm{~nm}$, forming a rough surface. These nanobricks gather together and grow along various directions, leading to the formation of a lot of pores which could increase the surface area of film. Through these pores, ions in the electrolyte can insert into or extract from the film more easily and efficiently, resulting from the reduced length of ion diffusion path. The cross-sectional view image (inset of Fig. 2(b)) shows that the film with a thickness of $\sim 320 \mathrm{~nm}$ has a good adhension to the substrate. Figure 2(c) shows the TEM image of the nanobricks scratched away from the substrate. One nanobrick with integral shape (length: $\sim 320 \mathrm{~nm}$ ) shows vertically joint angles. Figure 2(d) depicts the selected area electron diffraction (SAED) pattern of this nanobrick. Regular diffraction spots are obtained, proving it is single crystalline. The nanobrick has preferential growing direction along $c$ axis, corresponding to crystal planes of (002). The HRTEM image in Figure 2(e) from the edge of this nanobrick shows its crystal lattices of $0.38 \mathrm{~nm}$, corresponding to the $d$-spacing of (002) planes, in good agreement with Figure 2(d). Clear lattice fringes also indicate its single crystal quality.

To investigate the growth mechanism of the $\mathrm{H}-\mathrm{WO}_{3}$ films, the effects of seed layer, $\mathrm{H}_{2} \mathrm{O}_{2}$ and $\left(\mathrm{NH}_{4}\right)_{2} \mathrm{SO}_{4}$ on the products were also studied. Figures 3(a) and (b) show the SEM images of products grown without seed layer under different magnifications, while other conditions remain the same with Figure 2. Irregular bricks with different sizes rather than a film are obtained. These bricks are stacked disorderly and adhered to the substrate surface. This result indicates that crystal-seed-layer offers the nucleation sites for the growth of bricks, which is crucial on organizing these bricks into an ordered film system on the substrate. Figures 3(c) and (d) depict the SEM images of film grown without addition of $\left(\mathrm{NH}_{4}\right)_{2} \mathrm{SO}_{4}$. Thick yellowish film composed of gathered blocks with irregular shape and sizes are prepared. The nanoblock film shows a good adhesion to the substrate. The above result implies that $\left(\mathrm{NH}_{4}\right)_{2} \mathrm{SO}_{4}$ has a capping effect on the product. Figures 3(e) and (f) show the morphologies of products grown without addition of $\mathrm{H}_{2} \mathrm{O}_{2}$. Accumulated nanospheres with uniform sizes $(\sim 80 \mathrm{~nm})$ were synthesized. These nanospheres stacked intricately on the substrate are easily washed away by diwater. It seems that $\mathrm{H}_{2} \mathrm{O}_{2}$ has some chelating effect on directing the condensation of the $\left[\mathrm{WO}_{6}\right]$ and $\left[\mathrm{WO}_{5}-\mathrm{H}_{2} \mathrm{O}\right]$ octahedrons through the peroxo group. Moreover, it plays a role in linking the nucleus to the seed-layer coated surface. From the above result, it can be seen that $\mathrm{H}-\mathrm{WO}_{3}$ films can only be obtained on seed-layer-coated substrate with the addition of $\mathrm{H}_{2} \mathrm{O}_{2}$. The growth mechanism of the brick-like nanostructured film can be explained according to the following reactions:

$$
\begin{aligned}
& \mathrm{Na}_{2} \mathrm{WO}_{4}+2 \mathrm{HCl} \rightarrow \mathrm{H}_{2} \mathrm{WO}_{4} \downarrow+2 \mathrm{NaCl} \\
& \mathrm{H}_{2} \mathrm{WO}_{4}+\mathrm{xH}_{2} \mathrm{O}_{2} \rightarrow \mathrm{WO}_{3} \cdot \mathrm{xH}_{2} \mathrm{O}_{2} \cdot \mathrm{H}_{2} \mathrm{O}
\end{aligned}
$$

(Peroxopolytungstic acid) 

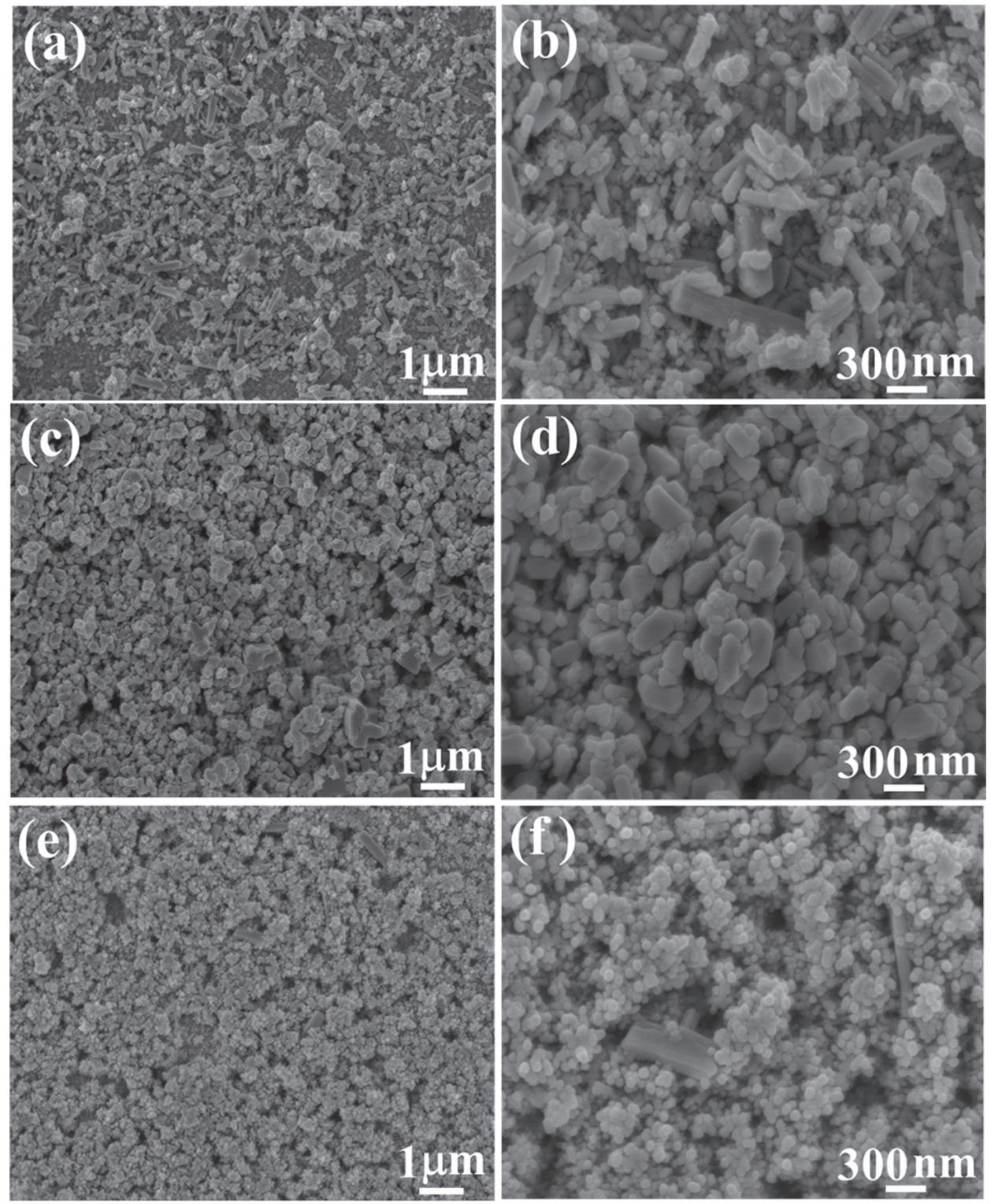

Fig. 3. (a) and (b) SEM images of the product grown without seed layer under different magnifications. (c) and (d) The product grown without addition of $\left(\mathrm{NH}_{4}\right)_{2} \mathrm{SO}_{4}$. (e) and (f) The product grown without addition of $\mathrm{H}_{2} \mathrm{O}_{2}$.

$$
\begin{gathered}
\mathrm{WO}_{3} \cdot \mathrm{xH}_{2} \mathrm{O}_{2} \cdot \mathrm{H}_{2} \mathrm{O} \rightarrow \mathrm{WO}_{3} \cdot 1 / 3 \mathrm{H}_{2} \mathrm{O} \text { (nucleus) } \\
+(\mathrm{x}+2 / 3) \mathrm{H}_{2} \mathrm{O}+\mathrm{x} / 2 \mathrm{O}_{2} \uparrow
\end{gathered}
$$

$\mathrm{WO}_{3} \cdot 1 / 3 \mathrm{H}_{2} \mathrm{O}$ (nucleus) $\rightarrow \mathrm{WO}_{3} \cdot 1 / 3 \mathrm{H}_{2} \mathrm{O}$ (nanobrick)

(capping agent: $\left.\left(\mathrm{NH}_{4}\right)_{2} \mathrm{SO}_{4}\right)$

$\mathrm{H}_{2} \mathrm{WO}_{4}$ precipitate was formed immediately after addition of $\mathrm{HCl}$ solution. Then it was rapidly dissolved by the existing hydrogen peroxide $\left(\mathrm{H}_{2} \mathrm{O}_{2}\right)$ in the precursor and peroxopolytungstic acid $\left(\mathrm{WO}_{3} \cdot \mathrm{xH}_{2} \mathrm{O}_{2} \cdot \mathrm{H}_{2} \mathrm{O}\right.$, PTA) was obtained. The peroxo group of the $\mathrm{H}_{2} \mathrm{O}_{2}$ behaves as a chelating agent on directing the condensation of the $\left[\mathrm{WO}_{6}\right]$ and $\left[\mathrm{WO}_{5}-\mathrm{H}_{2} \mathrm{O}\right]$ octahedrons. ${ }^{36,37}$ It decreases the functionality of aqueous precursors toward condensation and prevents precipitation. Without the addition of $\mathrm{H}_{2} \mathrm{O}_{2}$,
$\mathrm{H}_{2} \mathrm{WO}_{4}$ precipitate composed of numerous small clusters were formed and these clusters were further developed into nanospheres after hydrothermal process under high temperature. PTA can be easily decomposed at high temperature and a layer of $\mathrm{WO}_{3} \cdot 1 / 3 \mathrm{H}_{2} \mathrm{O}$ crystal nucleus was formed from the decomposition of PTA, and the seed-coating substrate acted as nucleation and growth sites. Without seed layer, irregular bricks attaching on the substrate surface rather than a film are obtained. Although there is no chemical reaction between the $\left(\mathrm{NH}_{4}\right)_{2} \mathrm{SO}_{4}$ and tungstic acid, the $\left(\mathrm{NH}_{4}\right)_{2} \mathrm{SO}_{4}$ will act as structure-directing and dispersing agents through both the anions $\left(\mathrm{SO}_{4}^{2-}\right)$ and cations $\left(\mathrm{NH}_{4}^{+}\right)$on the condensation of $\left[\mathrm{WO}_{6}\right]$ and $\left[\mathrm{WO}_{5}-\mathrm{H}_{2} \mathrm{O}\right]$ octahedrons. The brick-like nanostructures were grown eventually from the $\mathrm{WO}_{3} \cdot 1 / 3 \mathrm{H}_{2} \mathrm{O}$ 


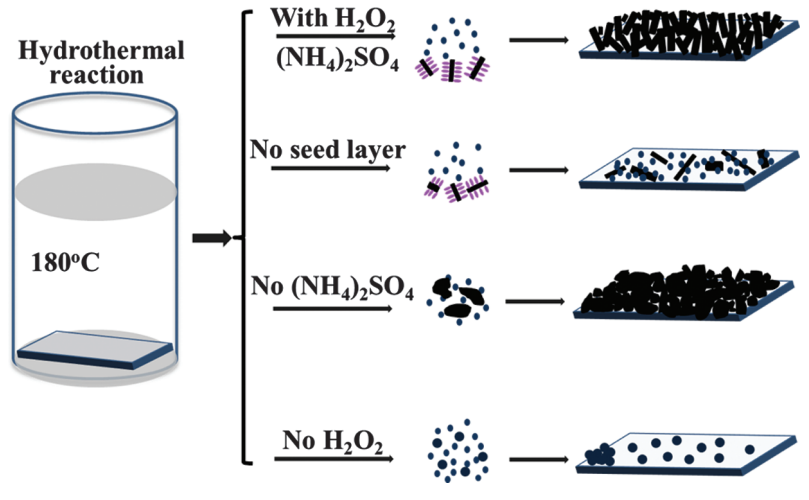

Fig. 4. (color online) A schematic illustration of the formation process for the products.

nucleus under the capping effect of $\left(\mathrm{NH}_{4}\right)_{2} \mathrm{SO}_{4}$, while block-like films were obtained without $\left(\mathrm{NH}_{4}\right)_{2} \mathrm{SO}_{4}$. Figure 4 schematically summarizes the formation process of as-prepared products under different hydrothermal conditions.

The thicknesses of the as-grown nanobrick films can be controlled by altering the concentration of precursor solution. A thicker film can be obtained under higher concentration. Moreover, the effects of the amount of $\left(\mathrm{NH}_{4}\right)_{2} \mathrm{SO}_{4}$ and $\mathrm{H}_{2} \mathrm{O}_{2}$ on the products were also investigated and shown in Figure 5. When the amount of $\left(\mathrm{NH}_{4}\right)_{2} \mathrm{SO}_{4}$ increased to $0.1 \mathrm{~g}$, some irregular particles were obtained and attached on the surface of substrate (shown in Figs. 5(a and b)), which may be due to the high ionic strength of the solution. While thin film made up of irregular microbricks was obtained when the amount of $\mathrm{H}_{2} \mathrm{O}_{2}$ was increased from 0.2 to $0.4 \mathrm{~g}$ (shown in Figs. 5(c and d)), with similar morphology to the previous reports. ${ }^{23}$

Cyclic voltammograms (CVs) normalized to the geometric area of the $\mathrm{H}-\mathrm{WO}_{3}$ film and $\mathrm{PB}$ film electrodes are shown in Figure 6(a), measured in $0.3 \mathrm{M} \mathrm{LiClO}_{4}$ in $\gamma$-BL as the electrolyte with a scan rate of $0.1 \mathrm{~V} / \mathrm{s}$. The PB film shows typical oxidation and reduction peaks at $0.23 \mathrm{~V}$ and $-0.37 \mathrm{~V}$, respectively, similar to the report. ${ }^{40}$ The $\mathrm{H}-\mathrm{WO}_{3}$ film shows oxidation peak at $-0.34 \mathrm{~V}$. Compared with the $\mathrm{H}-\mathrm{WO}_{3}$ film, the PB film has a higher current density, implying faster ions intercalation/deintercalation kinetics. During each scan, both films will reversibly change their colors from colorless to blue. For $\mathrm{H}-\mathrm{WO}_{3}$, this behavior is resulting from $\mathrm{Li}^{+}$and electron transfer between $\mathrm{W}^{6+}$ and $\mathrm{W}^{5+}$ according to the following reaction:

$$
\begin{gathered}
\mathrm{WO}_{3} \cdot 0.33 \mathrm{H}_{2} \mathrm{O}(\text { bleach })+\mathrm{xLi}^{+}+\mathrm{xe}^{-} \\
\leftrightarrow \mathrm{Li}_{\mathrm{x}} \mathrm{WO}_{3} \cdot 0.33 \mathrm{H}_{2} \mathrm{O}(\text { blue })
\end{gathered}
$$

while for $\mathrm{PB}$, the $\mathrm{EC}$ mechanism can be explained as follows:

$$
\begin{gathered}
\mathrm{Fe}(\mathrm{III})_{4}\left[\mathrm{Fe}(\mathrm{II})(\mathrm{CN})_{6}\right]_{3}(\mathrm{~PB}, \text { blue })+4 \mathrm{e}_{-}+4 \mathrm{Li}^{+} \\
\leftrightarrow \mathrm{Li}_{4} \mathrm{Fe}(\mathrm{II})_{4}\left[\mathrm{Fe}(\mathrm{II})(\mathrm{CN})_{6}\right]_{3} \text { (colorless) }
\end{gathered}
$$
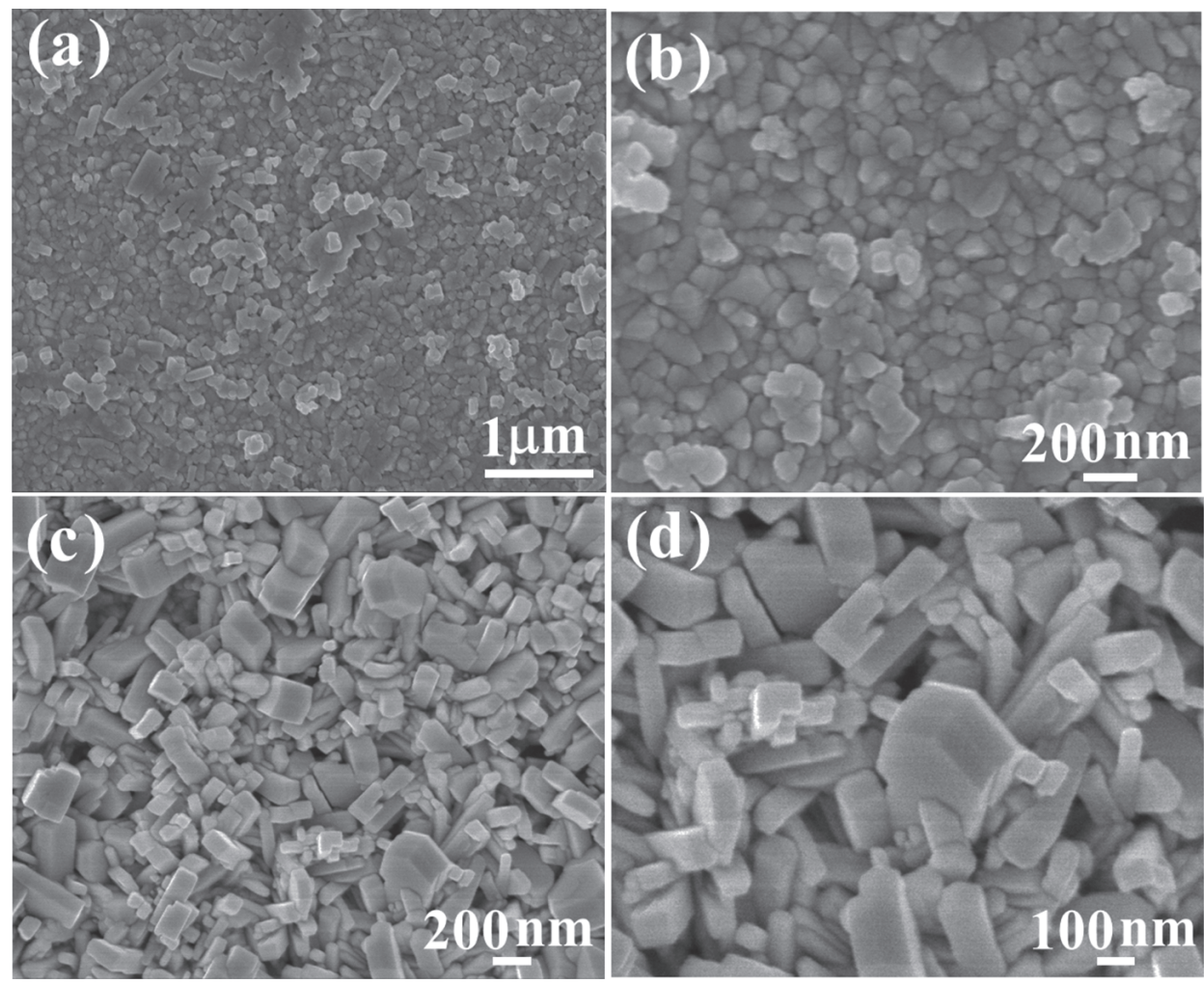

Fig. 5. SEM images of the products under different magnifications. (a) and (b) $0.1 \mathrm{~g}\left(\mathrm{NH}_{4}\right)_{2} \mathrm{SO}_{4}$; (c) and (d) $0.4 \mathrm{~g} \mathrm{H}_{2} \mathrm{O}_{2}$. 
The cyclic stability of the $\mathrm{H}-\mathrm{WO}_{3}$ film was also investigated by multiple cycles and shown in Figure 6(b). No significant shape change was observed, and only a small current reduction was found after 2000 cycles, indicating an excellent cyclic stability. According to the report, PB films also demonstrate outstanding stability. ${ }^{38}$ The long term cyclic stability is crucial for applications in energy efficient smart windows to compensate its relatively high cost.

Transmittance spectra of the complementary device and single PB layer device at bleached and colored state were compared (shown in Fig. 7(a)), operated under $\pm 0.8 \mathrm{~V}$ in $\gamma$-BL electrolyte $\left(0.3 \mathrm{M} \mathrm{LiClO}_{4}\right)$. The single PB layer device shows obvious broad optical modulation between bleached and colored states, especially in the range of $470 \mathrm{~nm}$ to $850 \mathrm{~nm}$, similar to the reports. ${ }^{41-44}$ The complementary device depicts a comparable high transmittance level at bleached state, indicating a highly transparent state of as-grown $\mathrm{H}-\mathrm{WO}_{3}$ films. When the device is colored, lower transmittance in the whole range is achieved, resulting from the complementary color contrast of $\mathrm{H}-\mathrm{WO}_{3}$ films. As a result, the complementary device demonstrates an improved optical regulation and an increased color contrast. Moreover, the complementary device shows a larger
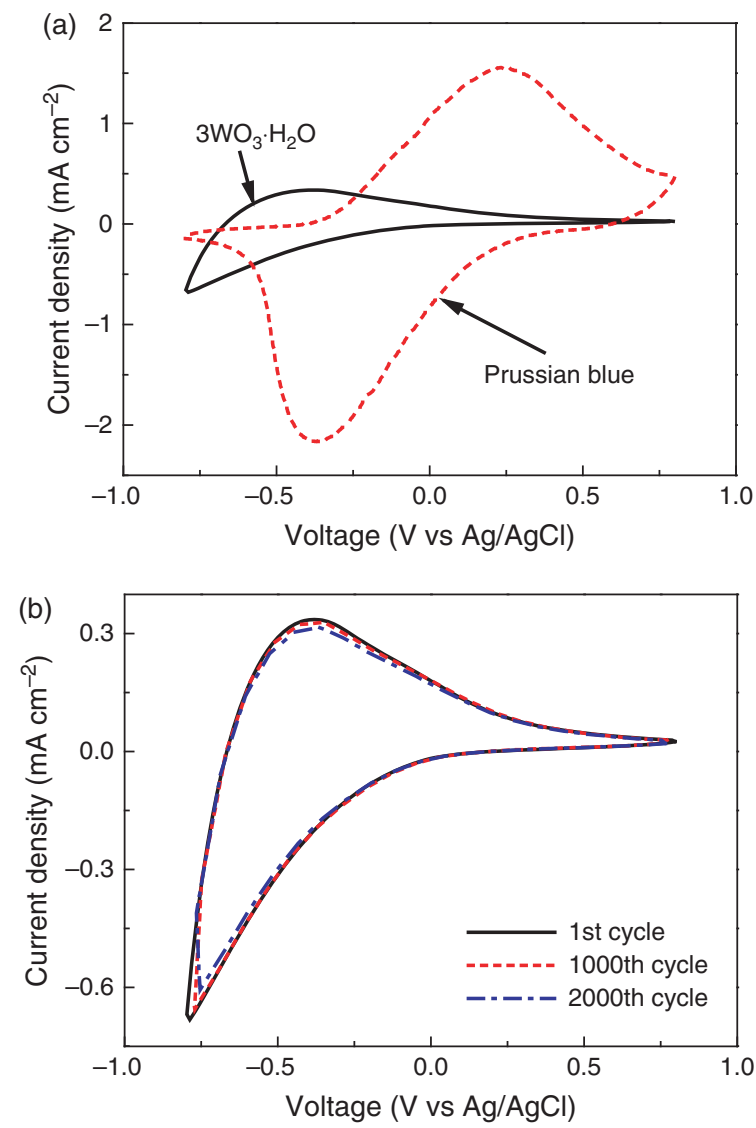

Fig. 6. (a) $\mathrm{CV}$ curves of as-prepared $\mathrm{H}-\mathrm{WO}_{3}$ film and electrodeposited PB film, measured in $0.3 \mathrm{M} \mathrm{LiClO}_{4} \gamma$-BL electrolyte at a scan rate of $0.1 \mathrm{~V} \mathrm{~s}^{-1}$, and (b) $\mathrm{CV}$ curves of the $\mathrm{H}-\mathrm{WO}_{3}$ film after 1st, 1000th and 2000th cycles. modulation in the infrared light due to a high absorbance and reflectance of crystalline $\mathrm{H}-\mathrm{WO}_{3}$ films, ${ }^{45}$ which property is highly desired in energy saving windows applications since a large amount of heat energy in infrared light is blocked from entering into the interior building. Transmittance spectra of the as prepared $\mathrm{H}-\mathrm{WO}_{3}$ film and the film at colored/bleached states were investigated and shown in Figure 7(b). The transmittance decreases obviously at the colored state above $400 \mathrm{~nm}$ compared to the bleached state. And a larger modulation in the infrared light region was observed compared with the single PB layer device. Moreover, the transmittance at bleached state is very close to the as-prepared state, indicating good reversibility of the film. Compared with the complementary device, the single $\mathrm{H}-\mathrm{WO}_{3}$ film device shows smaller transmittance regulation, resulting in the indistinctive optical contrast between colored complementary device and single PB layer device.

Figure 8(a) shows the in-situ switching transmittance response of the complementary device at $632.8 \mathrm{~nm}$, conducted by $\pm 0.8 \mathrm{~V}$ for $30 \mathrm{~s}$. Obvious color changes between transparent and blue can be seen during the switching. A maximum transmittance modulation $(\Delta \mathrm{T})$ of $\sim 30 \%$ between coloration and bleaching is achieved at this
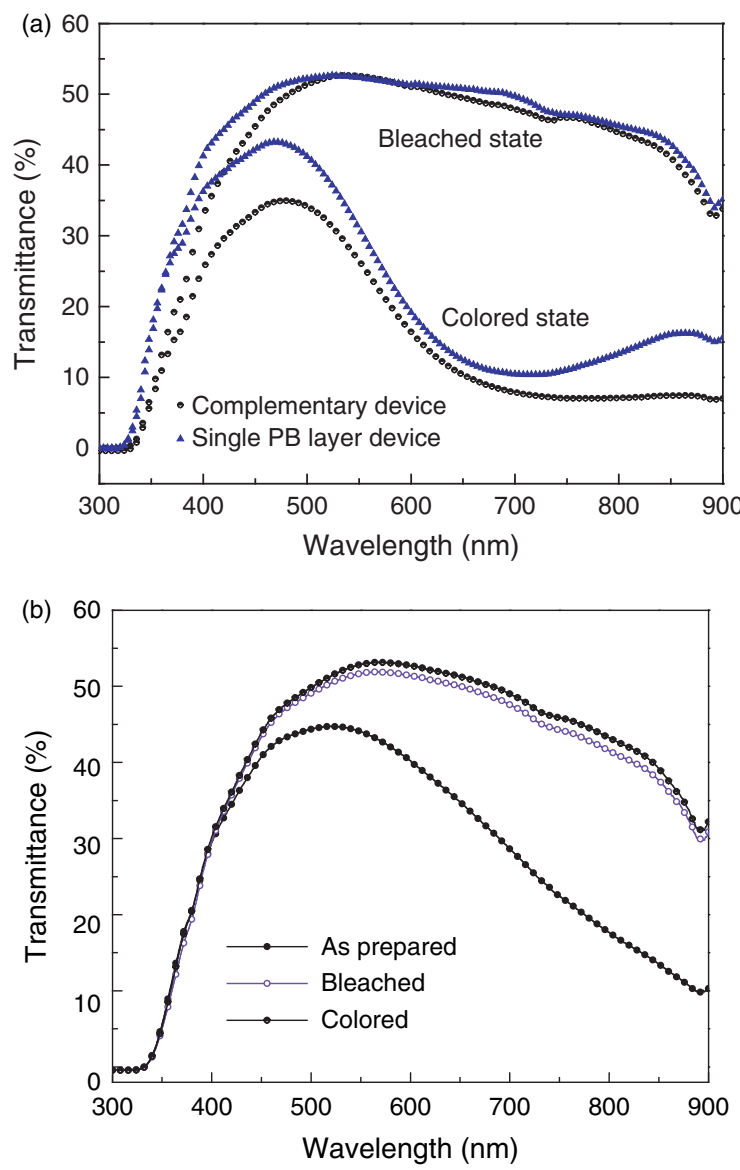

Fig. 7. (a) UV-vis transmittance spectra of the (a) complementary EC device and single PB layer device and (b) the single nanobrick film device at bleached and colored state under $\pm 0.8 \mathrm{~V}$, respectively. 

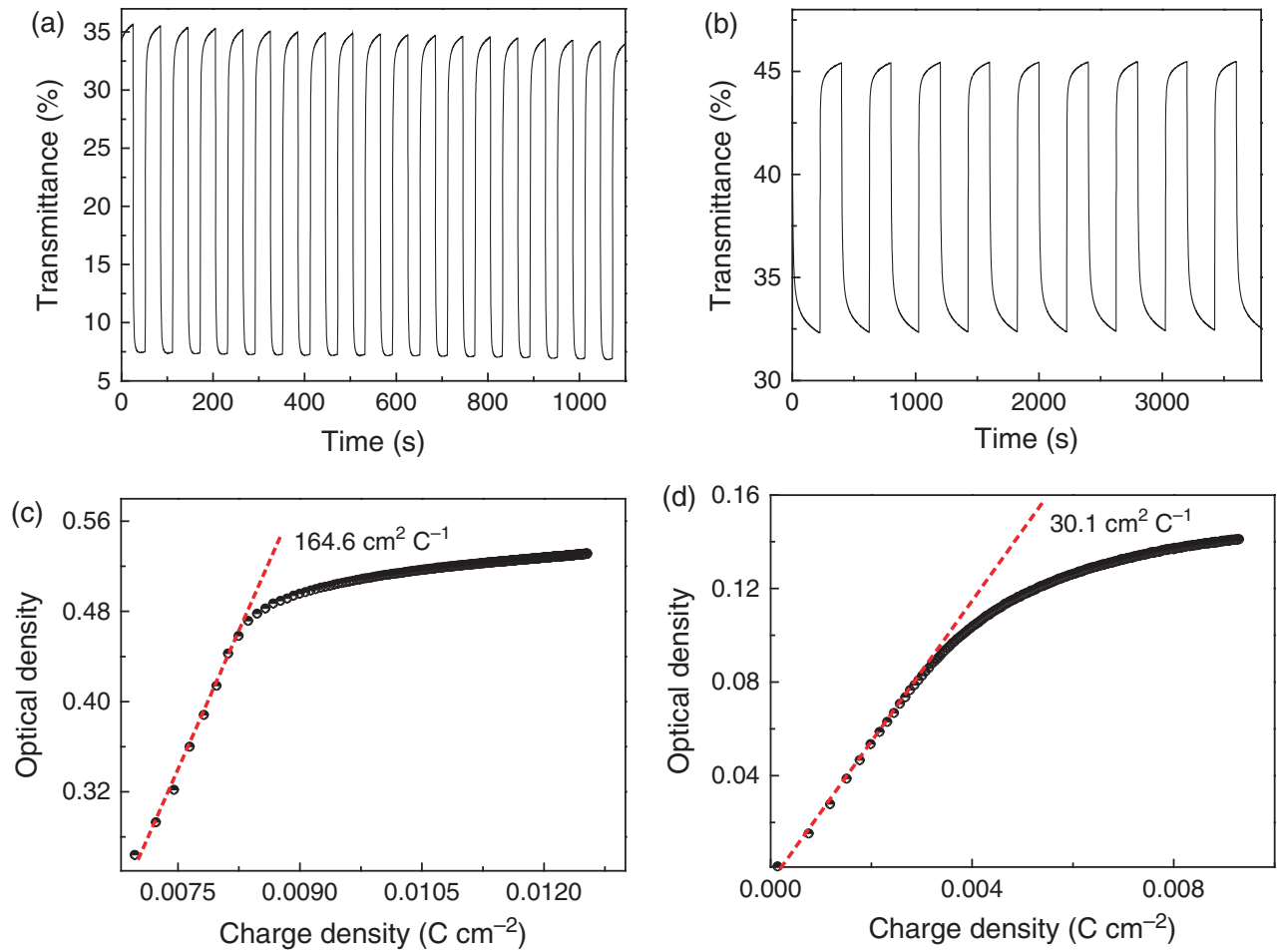

Fig. 8. (a) Switching time characteristics between the colored and bleached states for the complementary EC device and (b) the single $\mathrm{H}-\mathrm{WO} \mathrm{O}_{3}$ film device under $\pm 0.8 \mathrm{~V}$ at $632.8 \mathrm{~nm}$, respectively. (c) Optical density variation with respect to the charge density recorded at $632.8 \mathrm{~nm}$ for the complementary device and (d) the single $\mathrm{H}-\mathrm{WO}_{3}$ film device at $632.8 \mathrm{~nm}$.

wavelength, agreeing well with the transmittance spectra shown in Figure 7. The response time is extracted as the time for $90 \%$ transmittance change. The coloration time $\left(t_{c, 90 \%}\right)$ is found to be $1.8 \mathrm{~s}$ and bleaching time $\left(t_{b, 90 \%}\right)$ is $3.7 \mathrm{~s}$, respectively, both are much faster than the previous reported values. ${ }^{15,16}$ It is clear that the fast switching speed of the complementary device is mainly due to the fast switching kinetics of PB film, which account for the primary optical regulation. Although $\mathrm{H}-\mathrm{WO}_{3}$ films contribute a small complementary color contrast, it is crucial in regulating infrared light. The coloration/bleaching responses of the $\mathrm{H}-\mathrm{WO}_{3}$ films were also investigated and shown in Figure 8(b). A slower response of $t_{c, 90 \%}=51.5 \mathrm{~s}, t_{b, 90 \%}=$ $11.5 \mathrm{~s}$ and a smaller transmittance modulation $(\sim 13 \%)$ is found. However, the switching response is much faster than the reported microbrick and nanorods $\mathrm{WO}_{3}$ films. ${ }^{34,46}$ Fast switching speed is due to the small thickness and large surface area that resulting in a short diffusion path for ions.

Coloration efficiency $(C E)$ of the complementary device and single $\mathrm{WO}_{3}$ film device was also investigated and compared at $\lambda=632.8 \mathrm{~nm}$ (shown in Fig. 8(c)). CE, a crucial
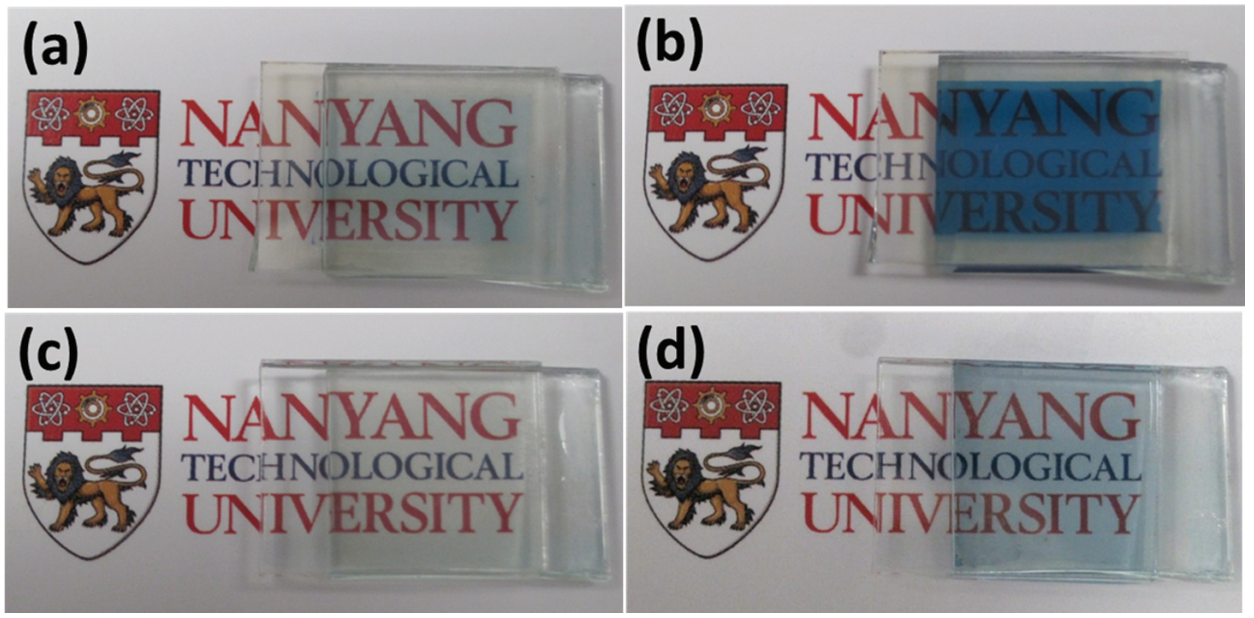

Fig. 9. Photographs of the complementary device at bleached state (a) and (b) colored state. Single $\mathrm{H}-\mathrm{WO}_{3}$ layer device at bleached (c) and (d) colored state under $\pm 0.8 \mathrm{~V}$, respectively. 
characteristic parameter for evaluating EC materials, is defined as the variation in optical density $(O D)$ per unit of charge $(Q)$ inserted into (or extracted from) the films, which can be calculated from the following equations:

$$
\begin{gathered}
C E=\Delta O D / \Delta Q \\
\Delta O D=\log \left(T_{b} / T_{c}\right)\left(\operatorname{or} \log \left(T_{c} / T_{b}\right)\right)
\end{gathered}
$$

where $T_{c}$ and $T_{b}$ refer to the transmittance of the film in its colored and bleached states, respectively. The $C E$ value is extracted as the slope of the line fitted to the linear region of the $\triangle O D$ versus $\triangle Q$ curve. A high value of $C E$ indicates that the EC film exhibits a large optical modulation with a small charge inserted (or extracted), which is related the porosity, crystal sizes and phase structures of the film. For the complementary device, the $C E$ value is calculated to be $164.6 \mathrm{~cm}^{2} \mathrm{C}^{-1}$, which is larger than the reported value $\left(\sim 140 \mathrm{~cm}^{2} \mathrm{C}^{-1}\right){ }^{15,16}$ The $O D$ variation is dramatic initially with the insertion of ions, then it gets smaller and smaller and finally gets stabilized after more ions inserted into the films. An inflection point at $\sim 0.008 \mathrm{C} \mathrm{cm}^{-2}$ is observed, and the $O D$ quickly gets stabilized after it. For the single $\mathrm{H}-\mathrm{WO}_{3}$ film (Fig. 8(d)), a $C E$ value of $30.1 \mathrm{~cm}^{2} \mathrm{C}^{-1}$ is obtained, which is comparable to the reported value. ${ }^{34}$

Photographs of the complementary EC device and the single $\mathrm{H}-\mathrm{WO}_{3}$ film device are shown in Figure 9. The complementary device depicts a higher contrast between bleached and colored state than the single $\mathrm{H}-\mathrm{WO}_{3}$ film one. The device is promisingly applied in energy efficient smart windows and large area information displays.

\section{CONCLUSIONS}

Uniform and highly adhesive nanobrick $\mathrm{H}-\mathrm{WO}_{3}$ films were assembled on FTO glass substrate by a facile and template-free crystal-seed-assisted hydrothermal method. The effects of seed-layer, $\left(\mathrm{NH}_{4}\right)_{2} \mathrm{SO}_{4}$ and $\mathrm{H}_{2} \mathrm{O}_{2}$ on the products are studied. The seed-layer and $\mathrm{H}_{2} \mathrm{O}_{2}$ are vital in assembling the nanostructures into a thin film on the substrate, and both $\left(\mathrm{NH}_{4}\right)_{2} \mathrm{SO}_{4}$ and $\mathrm{H}_{2} \mathrm{O}_{2}$ have influences on the products' morphologies. The as-synthesized orthorhombic $\mathrm{H}-\mathrm{WO}_{3}$ films show good cyclic stability, comparable switching response $\left(t_{c, 90 \%}=51.5 \mathrm{~s}, t_{b, 90 \%}=\right.$ $11.5 \mathrm{~s})$ and $C E$ value $\left(30.1 \mathrm{~cm}^{2} \mathrm{C}^{-1}\right)$. A complementary device made up of $\mathrm{H}-\mathrm{WO}_{3}$ and $\mathrm{PB}$ film is fabricated and demonstrates highly improved EC performance. This device shows much faster coloration/bleaching response $\left(t_{c, 90 \%}=1.8 \mathrm{~s}, t_{b, 90 \%}=3.7 \mathrm{~s}\right)$, larger $C E$ value $\left(164.6 \mathrm{~cm}^{2} \mathrm{C}^{-1}\right)$ and increased color contrast. The complementary device is prospectively applied in smart windows and displays, and the as-synthesized $\mathrm{H}-\mathrm{WO}_{3}$ films may find more applications in gas sensors and electronic devices.
Acknowledgments: The authors would like to thank the financial support from the Science and Engineering Research Council, Agency for Science, Technology and Research (A*STAR) of Singapore (project Nos. 092101 0057 and 092151 0088), Singapore National Research Foundation (NRF-RF-2009-09 and NRF-CRP-6-2010-2), and National Natural Science Foundation of China (NSFC) (project Nos. 61006037 and 61076015).

\section{References and Notes}

1. C. R. Granqvist, Nat. Mater. 5, 89 (2006).

2. C. G. Granqvist, Electrochim. Acta 44, 3005 (1999).

3. C. G. Granqvist, Sol. Energy Mater. Sol. Cells 60, 201 (2000).

4. G. A. Niklasson and C. G. Granqvist, J. Mater. Chem. 17, 127 (2007).

5. W. Cheng, E. Baudrin, B. Dunn, and J. I. Zink, J. Mater. Chem. 11, 92 (2001).

6. S. I. Cho, W. J. Kwon, S. J. Choi, P. Kim, S. A. Park, J. Kim, S. J. Son, R. Xiao, S. H. Kim, and S. B. Lee, Adv. Mater. 17, 171 (2005).

7. S. I. Cho, R. Xiao, and S. B. Lee, Nanotechnology 18, 405705 (2007).

8. D. T. Gillaspie, R. C. Tenent, and A. C. Dillon, J. Mater. Chem. 20, 9585 (2010).

9. R. D. Rauh, Electrochim. Acta 44, 3165 (1999).

10. R. Baetens, B. P. Jelle, and A. Gustavsen, Sol. Energy Mater. Sol. Cells 94, 87 (2010).

11. T. J. Richardson, J. L. Slack, R. D. Armitage, R. Kostecki, B. Farangis, and M. D. Rubin, Appl. Phys. Lett. 78, 3047 (2001).

12. R. J. Mortimer, A. L. Dyer, and J. R. Reynolds, Displays 27, 2 (2006).

13. S. H. Lee, R. Deshpande, P. A. Parilla, K. M. Jones, B. To, A. H. Mahan, and A. C. Dillon, Adv. Mater. 18, 763 (2006).

14. J. Scarminio, A. Lourenco, and A. Gorenstein, Thin Solid Films 302, 66 (1997).

15. A. Kraft and M. Rottmann, Sol. Energy Mater. Sol. Cells 93, 2088 (2009).

16. A. Kraft, M. Rottmann, and K. H. Heckner, Sol. Energy Mater. Sol. Cells 90, 469 (2006).

17. R. J. Mortimer, Electrochim. Acta 44, 2971 (1999).

18. S. Y. Park, J. M. Lee, C. Noh, and S. U. Son, J. Mater. Chem. 19, 7959 (2009).

19. S. A. Sapp, G. A. Sotzing, J. L. Reddinger, and J. R. Reynolds, $A d v$. Mater. 8, 808 (1996).

20. J. Zhang, J. P. Tu, X. H. Xia, Y. Qiao, and Y. Lu, Sol. Energy Mater. Sol. Cells 93, 1840 (2009).

21. C. G. Granqvist, Adv. Mater. 15, 1789 (2003).

22. R. Kirchgeorg, S. Berger, and P. Schmuki, Chem. Commun. 47, 1000 (2011).

23. J. Zhang, J. P. Tu, X. H. Xia, X. L. Wang, and C. D. Gu, J. Mater. Chem. 21, 5492 (2011).

24. C. H. Chen, S. J. Wang, R. M. Ko, Y. C. Kuo, K. M. Uang, T. M. Chen, B. W. Liou, and H. Y. Tsai, Nanotechnology 17, 217 (2006).

25. E. B. Franke, C. L. Trimble, M. Schubert, J. A. Woollam, and J. S. Hale, Appl. Phys. Lett. 77, 930 (2000).

26. I. Valyukh, S. Green, H. Arwin, G. A. Niklasson, E. Wackelgard, and C. G. Granqvist, Sol. Energy Mater. Sol. Cells 94, 724 (2010).

27. Y. Yamada, K. Tabata, and T. Yashima, Sol. Energy Mater. Sol. Cells 91, 29 (2007).

28. P. X. Feng, X. P. Wang, H. X. Zhang, B. Q. Yang, Z. B. Wang, A. Gonzalez-Berrios, G. Morell, and B. Weiner, J. Phys. D: Appl. Phys. 40, 5239 (2007). 
Jiao et al. A Complementary Electrochromic Device with Highly Improved Performance Based on Brick-Like $3 \mathrm{WO}_{3} \cdot \mathrm{H}_{2} \mathrm{O}$ Film

29. K. Sivula, F. Le Formal, and M. Gratzel, Chem. Mater. 21, 2862 (2009).

30. S. H. Baeck, T. Jaramillo, G. D. Stucky, and E. W. McFarland, Nano Lett. 2, 831 (2002)

31. N. R. de Tacconi, C. R. Chenthamarakshan, K. Rajeshwar, T. Pauporte, and D. Lincot, Electrochem. Commun. 5, 220 (2003).

32. B. Yang, P. R. F. Barnes, W. Bertram, and V. Luca, J. Mater. Chem. 17, 2722 (2007).

33. B. Yang, Y. J. Zhang, E. Drabarek, P. R. F. Barnes, and V. Luca, Chem. Mater. 19, 5664 (2007).

34. Z. H. Jiao, X. W. Sun, J. M. Wang, L. Ke, and H. V. Demir, J. Phys. D: Appl. Phys. 43, 285501 (2010).

35. Z. H. Jiao, J. M. Wang, L. Ke, X. W. Sun, and H. V. Demir, Acs Appl. Mat. Inter. 3, 229 (2011).

36. J. Livage and G. Guzman, Solid State Ionics 84, 205 (1996).

37. J. Livage and D. Ganguli, Sol. Energy Mater. Sol. Cells 68, 365 (2001).

38. K. Itaya, K. Shibayama, H. Akahoshi, and S. Toshima, J. Appl. Phys. 53, 804 (1982).
39. M. F. Daniel, B. Desbat, and J. C. Lassegues, J. Solid State Chem. 67, 235 (1987)

40. M. J. Wang, G. J. Fang, L. Y. Yuan, H. H. Huang, Z. H. Sun, N. S. Liu, S. H. Xia, and X. Z. Zhao, Nanotechnology 20, 185304 (2009).

41. S. Hara, H. Tanaka, T. Kawamoto, M. Tokumoto, M. Yamada, A. Gotoh, H. Uchida, M. Kurihara, and M. Sakamoto, Jpn. J. Appl. Phys. Part 2 46, L945 (2007)

42. S. Hara, H. Shiozaki, A. Omura, H. Tanaka, T. Kawamoto, M. Tokumoto, M. Yamada, A. Gotoh, M. Kurihara, and M. Sakamoto, Appl. Phys. Exp. (APEX). 1, 104002 (2008).

43. A. Omura, H. Shiozaki, S. Hara, T. Kawamoto, A. Gotoh, M. Kurihara, M. Sakamoto, and H. Tanaka, IEICE Trans. Electron. E91C, 1887 (2008).

44. A. Omura, H. Tanaka, M. Kurihara, M. Sakamoto, and T. Kawamoto, Phys. Chem. Chem. Phys. 11, 10500 (2009).

45. A. Agrawal, J. P. Cronin, and R. Zhang, Sol. Energy Mater. Sol. Cells 31, 9 (1993).

46. J. M. Wang, E. Khoo, P. S. Lee, and J. Ma, J. Phys. Chem. C 112, 14306 (2008).

Received: 28 September 2011. Accepted: 25 November 2011. 